\title{
A
}

Acta HealthMedica

Volume 2, Issue 2, April-June 2017, Pages: 165, DOI: http://dx.doi.org/10.19082/ah165

\section{SENDING LABORATORY RESULTS VIA HOSPITAL WEBSITE: PATIENTS' VIEWPOINTS AND PRIORITIES}

\author{
Azam Sabahi ${ }^{1,2}$, Leila Ahmadian $^{3}$
}

1: Medical records Expert, Ferdows Chamran hospital, Birjand University of Medical Sciences, South Khorasan, Iran

2: MSc Student of Health Information Technology, Faculty of Management and Medical Information Sciences, Kerman University of Medical Sciences, Kerman, Iran

3: Associate Professor of Medical Informatics, Medical Informatics Research Center, Institute for Futures Studies in Health, Kerman University of Medical Sciences, Kerman, Iran

\section{Correspondence:}

Leila Ahmadian, Tel: 09132969728, Fax: 03431325406, E-mail: ahmadianle@yahoo.com

\section{TYPE OF ARTICLE: CONFERENCE ABSTRACT}

\begin{abstract}
Introduction: One of the departments in the hospital that can provide health services is the laboratory department. This study examined patients' satisfaction, viewpoints and priorities to receive laboratory results before and after receiving results via website.

Methods: This was a cross-sectional descriptive and analytic study that was carried out at Chamran hospital in Ferdows in 2015. This study consisted of three phases. The first phase: In order to determine the priorities and patients' satisfaction, 200 patients were enrolled. The second phase: Of the participants, 95 were willing to receive laboratory results via the website. In this phase, after designing the portal, laboratory results of every person based on priorities and their views were sent to the portal. The third phase: Evaluating patients' satisfaction after receiving laboratory results through the portal using electronic questionnaires. Data analysis was done by SPSS software version 19 using descriptive and analytic statistics including McNemar and Marginal Homogeneity.

Results: Receiving laboratory results along with information such as doctor's name $(\mathrm{p}=0.024)$ and date of the laboratory test ( $\mathrm{p}-0.021)$ after receiving the results via the Web site, most were welcomed. After receiving the results, more participants significantly mentioned that receiving results through a website was very much effective $(\mathrm{n}=80,84.2 \%, \mathrm{n}=50,52.6 \%, \mathrm{p}<0.0001)$.

Conclusion: The results of this study showed that regarding the patients' priorities and views regarding electronic communication with laboratory departments, patients can lead tumor effective communication and are more satisfied.

KEYWORDS: Laboratory Information Systems, Online services, Patient preference, Website
\end{abstract}

\footnotetext{
Abstracts of First National Congress of Medical Informatics, Mashhad, Iran, February 2017

(C) 2017 The Authors. This is an open access article under the terms of the Creative Commons Attribution-NonCommercialNoDerivs License, which permits use and distribution in any medium, provided the original work is properly cited, the use is non-commercial and no modifications or adaptations are made.
} 